\title{
Study on Treatment of Secondary Sedimentation Wastewater by Sodium Hypochlorite Oxidation, Activated Carbon Adsorption and Coagulation Precipitation
}

\author{
Bin Liu, Cheng-yuan $\mathrm{Hu}$ \\ Yancheng Environmental Monitoring Center of Jiangsu province, Jiangsu, 224000, China
}

\begin{abstract}
In this paper, $\mathrm{COD}_{\mathrm{Cr}}$ index was adopted as the test item, and the wastewater from the secondary sedimentation tank of a sewage treatment plant selected was treated by the method of "sodium hypochlorite oxidation activated carbon adsorption - coagulation precipitation". The results showed that the removal rate of $\mathrm{COD}_{\mathrm{Cr}}$ reached $57.3 \%$ by the treatment of "sodium hypochlorite oxidation - activated carbon adsorption - coagulation precipitation". Therefore, this method can improve the removal rate of $\mathrm{COD}_{\mathrm{Cr}}$, can make the wastewater discharging standard, and for the project provides data support to better treatment of industrial wastewater.

Keywords Secondary settling tank; $\mathrm{COD}_{\mathrm{Cr}}$; Fenton oxidation; Sodium hypochlorite oxidation; Treat reach the standard

DOI: $10.7176 / \mathrm{CER} / 11-6-01$

Publication date:July $31^{\text {st }} 2019$

\section{Introduction}

The rapid development of economy not only promotes social progress, but also brings harm to the environment, which makes pollution become a big problem, among which water pollution is the top priority. In order to better control the water pollution, in the town built a sewage treatment plant in China, the industrial wastewater or sewage treatment, so as to improve water quality ${ }^{[1-4]}$, in which the second pond, the sewage treatment plant is one of the key processing unit, will directly affect the biochemical treatment system of effluent water quality and return sludge concentration, its running state is related to water index ${ }^{[5-6]}$ for the factory. To this, this study will be activated carbon adsorption materials as well as the coagulant polyaluminium chloride (PAC) and polyacrylamide (PAM) is applied to the sodium hypochlorite oxidation - activated carbon adsorption and coagulation precipitation "integrated oxidation method ${ }^{[7-12]}$, to deal with the second pond wastewater, by improving the removal rate of $\mathrm{COD}_{\mathrm{Cr}}$, prompting wastewater treatment standards, to provide experimental data for water treatment engineering.
\end{abstract}

\section{Experiment}

2.1 Routine water quality indexes

The $\mathrm{pH}$ value was determined by glass electrode method, chromaticity was determined by dilution ratio method, total phosphorus was determined by ammonium molybdate spectrophotometry, and $\mathrm{COD}_{\mathrm{Cr}}$ was determined by potassium dichromate method ${ }^{[13]}$.

\subsection{Sodium hypochlorite oxidation of wastewater}

2.2.1 Oxidation experiment and adsorption-coagulation secondary treatment

Under the $\mathrm{pH}$ condition of the raw water from the secondary sedimentation tank, $0.2 \% 0,0.5 \%, 1 \%$, $1.2 \%$ and $1.5 \%$ sodium hypochlorite solutions (free chlorine 5.2\%) were added for oxidation reaction for $1 \mathrm{~h}$. After the reaction, partial samples were taken for static treatment. After precipitation, the supernatant was taken to detect $\mathrm{COD}_{\mathrm{Cr}}$

The effluent from the above five groups of experiments was added with $0.5 \%$ activated carbon for adsorption reaction for $1 \mathrm{~h}$. After the reaction, $10 \% \mathrm{PAC}$ solution of $2 \mathrm{~mL}$ and $2.5 \% \mathrm{PAM}$ solution of $2 \mathrm{~mL}$ were added. After static precipitation, the supernatant was taken to detect $\mathrm{COD}_{\mathrm{Cr}}$. Under this reaction condition, the flogs have good sedimentation performance, and activated carbon powder is the agglomeration sedimentation within 30 seconds.

\subsubsection{Activated carbon adsorption - coagulation sedimentation}

Under the condition of raw water $\mathrm{pH}$, the dosage of fixed sodium hypochlorite solution was $1 \%$. After oxidation reaction for $1 \mathrm{~h}$, activated carbon of $0.5 \%$ was added. After adsorption for $1 \mathrm{~h}, 10 \%$ PAC solution of $2 \mathrm{~mL}$ and $2.5 \%$ PAM solution of $2 \mathrm{~mL}$ were added for flocculation and precipitation.

\section{Results and discussion}

3.1 Test results of raw water samples

The raw water samples were tested according to the method described in 1.1 . The water quality of the raw water 
samples was light brown, and their $\mathrm{pH}, \mathrm{COD}_{\mathrm{Cr}}$, total phosphorus and chromaticity were shown in Table 1.

Table 1 the second pond water quality inspection situation

\begin{tabular}{ccccc}
\hline Water source & $\mathrm{pH}$ & $\begin{array}{c}\mathrm{COD}_{\mathrm{Cr}} \\
\mathrm{mg} / \mathrm{L}\end{array}$ & Total phosphorus mg/L & $\begin{array}{c}\text { Chroma } \\
\text { Diluted multiples }\end{array}$ \\
\hline Secondary sedimentation tank effluent & 7.77 & 183 & 0.4 & 50 \\
\hline
\end{tabular}

\subsection{Sodium hypochlorite oxidation experiment}

3.2.1 Oxidation effect of sodium hypochlorite

As described in 2.3.1, the $\mathrm{COD}_{\mathrm{Cr}}$ of water samples was determined at different sodium hypochlorite content, and the adsorption-coagulation secondary treatment was performed for each water sample. The $\mathrm{COD}_{\mathrm{Cr}}$ of supernatant, sodium hypochlorite content and the effect of adsorption-coagulation secondary treatment on the oxidation effect were also measured, as shown in Fig. 1.

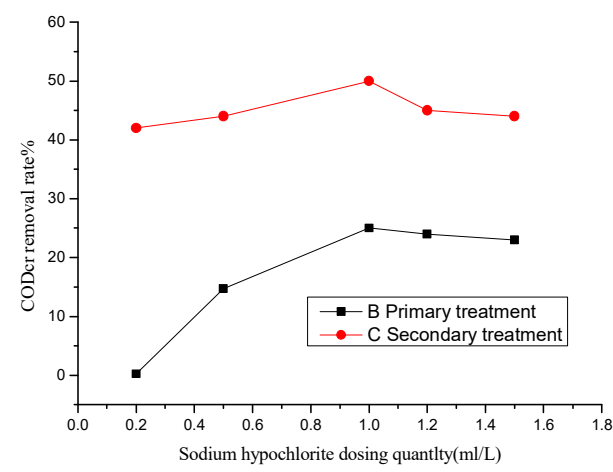

Fig. 1 influence of primary treatment and secondary treatment on $\mathrm{COD}_{\mathrm{Cr}}$ removal rate

Fig. 1 shows that the removal rate of $\mathrm{COD}_{\mathrm{Cr}}$ increased significantly with the increase of sodium hypochlorite dosage. When $0.2 \%, 0.5 \%$ and $1 \%$ sodium hypochlorite were added to water samples, the removal rate of $\mathrm{COD}_{\mathrm{Cr}}$ showed a linear increase. At the dosage of $0.2 \%$, the removal rate of $\mathrm{COD}_{\mathrm{Cr}}$ was only $3 \%$, while at the dosage of $1 \%$, the removal rate of $\mathrm{COD}_{\mathrm{Cr}}$ was increased to $25.9 \%$. Therefore, when the dosage of sodium hypochlorite was $1 \%$, the removal rate of $\mathrm{COD}_{\mathrm{Cr}}$ in wastewater was the highest and fenton oxidation treatment had the best effect.

Under the condition of $1 \%$ sodium hypochlorite oxidized water, the secondary treatment of activated carbon adsorption coagulation further strengthened the removal effect of $\mathrm{COD}_{\mathrm{Cr}}$. The concentration of $\mathrm{COD}_{\mathrm{Cr}}$ could be reduced from $135.5 \mathrm{mg} / \mathrm{L}$ to $92 \mathrm{mg} / \mathrm{L}$, and the removal rate of $\mathrm{COD}_{\mathrm{Cr}}$ increased by $23.8 \%$ on the basis of the original $25.9 \%$, and finally reached $49.7 \%$. However, $\mathrm{COD}_{\mathrm{Cr}}$ did not continue to decline in the simple secondary treatment of $1 \%$ sodium hypochlorite oxidized water, indicating that activated carbon adsorption played a dominant role in the secondary treatment.

3.2.2 Influence of activated carbon dosage

As described in 2.3.2, $\mathrm{COD}_{\mathrm{Cr}}$ of supernatant was determined at different amounts of activated carbon, and its influence on secondary treatment was shown in Fig. 2.

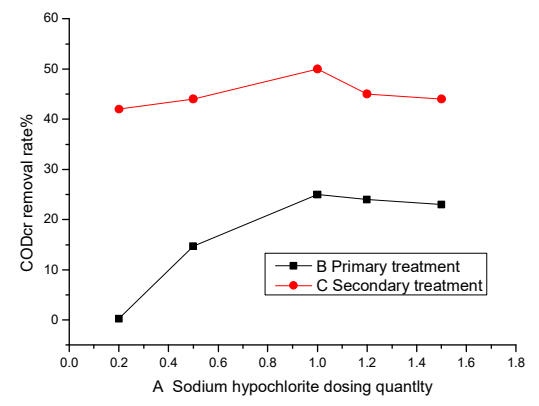

Fig. 2 effect of activated carbon on CODcr removal rate

It can be seen from Fig. 2 that the effect of adsorption-coagulation secondary treatment increases with the addition of activated carbon, and the effect of adsorption-coagulation secondary treatment greatly enhances the removal of $\mathrm{COD}_{\mathrm{Cr}}$ from the oxidized water of sodium hypochlorite. When the dosage was $0.1 \%$, the removal effect of $\mathrm{COD}_{\mathrm{Cr}}$ could be increased by $16.2 \%$. When the dosage was $0.5 \%$, the removal effect of $\mathrm{COD}_{\mathrm{Cr}}$ was 
increased by $40.9 \%$, and the total removal rate of $\mathrm{COD}_{\mathrm{Cr}}$ was $56.2 \%$.

3.2.3 Activated carbon adsorption - coagulation sedimentation experiments

As described in 2.3.3, CODCr of water samples was determined under the best conditions, and the treatment effect was shown in Table 2

Table2 Processing effects under optimal conditions

\begin{tabular}{cccc}
\hline conditions & $\begin{array}{c}\mathrm{COD}_{\mathrm{Cr}} \\
\mathrm{mg} / \mathrm{L}\end{array}$ & $\begin{array}{c}\mathrm{COD}_{\mathrm{Cr}} \text { average } \\
\mathrm{mg} / \mathrm{L}\end{array}$ & $\begin{array}{c}\mathrm{COD}_{\mathrm{Cr}} \\
\text { Removal rate\% }\end{array}$ \\
\hline \multirow{2}{*}{ Best condition } & 82 & 78 & 57.3 \\
\hline
\end{tabular}

It can be seen from Table 3 that under the optimal conditions of sodium hypochlorite oxidation experiment, the total removal rate of CODCr can reach $57.3 \%$, and the CODCr value of wastewater can be reduced from 183 to 78 , meeting the pollutant discharge standard and meeting the discharge standard, providing data support for better treatment of industrial wastewater.

\section{Conclusion}

Based on the data of the above projects, we can know that the effluent quality from the second sedimentation tank of the sewage plant can be treated with the oxidation method of "sodium hypochlorite oxidation - activated carbon adsorption - coagulation precipitation" to reach the standard. Through the treatment of "sodium hypochlorite oxidation - activated carbon adsorption - coagulation precipitation", when the sodium hypochlorite solution dosage is $1 \%$, the oxidation reaction time is $1 \mathrm{~h}$ and $0.5 \%$ of activated carbon is added for the secondary treatment, the removal effect is the best. At this time, the removal rate of $\mathrm{COD}_{\mathrm{Cr}}$ reaches $57.3 \%$. Among them, the contribution rate of the wastewater itself to $\mathrm{COD}_{\mathrm{Cr}}$ removal was $9.3 \%$, and the mechanical stirring method was better than the aeration stirring method.

Meanwhile, from the perspective of economic benefits, the treatment costs of this treatment method are shown in Table 3. Therefore, this method can improve the removal rate of $\mathrm{COD}_{\mathrm{Cr}}$, prompted wastewater discharging standard, can meet the economic benefits of sewage treatment plant, and for the project provides data support to better treatment of industrial wastewater.

Table 3 Cost of sodium hypochlorite treatment

\begin{tabular}{cccc}
\hline Drug kinds & $\begin{array}{c}\text { Unit price } \\
\text { yuan } / \mathrm{t}\end{array}$ & $\begin{array}{c}\text { The dosage } \\
\mathrm{g} / \mathrm{L}\end{array}$ & $\begin{array}{c}\text { Processing cost } \\
\text { yuan } / \mathrm{t}\end{array}$ \\
\hline Sodium hypochlorite & 700 & 1 & 0.7 \\
PAC & 2000 & 0.2 & 0.4 \\
PAM & 9000 & 0.005 & 0.045 \\
Activated carbon & 3500 & 0.5 & 1.75 \\
Sludge (dry) & 3000 & 0.3 & 0.9 \\
Total & & & 3.795 \\
\hline
\end{tabular}

\section{Acknowledgement}

The research is supported by a Project Funded by Innovation and entrepreneurship training program for college students in Jiangsu province (2019).

\section{Reference}

[1] He-tian Chen, Wei Ii, Ri-xin Ding, Feng Luo, Guan-ti Xie, Ming-zhu Miao. Discussion on the construction of intelligent operation platform for sewage treatment plant [J]. Water supply and drainage, 2016,42 (S1) : 292-296.

[2] Zhan-peng Jiang, Hong-wei Yang. Environmental engineering (third edition)[M], Beijing: higher education press, 2003:73-74.

[3] Yong-ling Chen, Yi-ning Zheng, Dun-yu Zhu. Process design of sludge system in sewage treatment plant upgrade [J]. China water supply and drainage, 2013,29 (10) : 40-43.

[4] Xiao-dong Li, Jng Feng, Jie Liang, Qing CAI, Lu Huang, Lin Shi,Guang-ming Zeng. Research on optimization of secondary sedimentation tank based on numerical response surface method [J]. Journal of environmental science, 2012,32 (9) : 2279-2286.

[5]Environmental science and technology, 2011,34(6) : 163-166. (in Chinese with English abstract)

[6] Xin Liu, Yong Zheng, Mei-hua Fu, Li-juan Ma. Selection of sedimentation tank type in water purification station of water supply system of thermal power plant [J]. Environment and development, 2017,19 (1) : 98100 .

[7] Cong Zhao, Jing zhang. progress of fenton oxidation technology in wastewater treatment [J]. Environmental science and management, 2015, 39(5):83-87. (in Chinese)

[8] Qing-guo Chen, Mei Liu. Treatment of Oil Field Wastewater after Chemical Flooding by Fenton Oxidation 
Combined with Bio - degradation [J]. Journal of Meteorological and Environmental research, 2015, 6 (3) : 37 to 40 .

[9] Jing Wang, Zeng-feng. Yang. Application of Fenton oxidation in wastewater treatment [J]. Environmental science and technology, 2011,4 (11) : 104-108. (in Chinese)

[10]GB 6920-1986 water quality -- determination of $\mathrm{pH}$ value -- glass electrode method (S).

[11]GB 11903-1989 determination of water color (S).

[12]GB 11893-1989 water quality -- determination of total phosphorus -- ammonium molybdate spectrophotometric method (S).

[13]GB 11914-1989 chemical oxygen demand for water -- determination of dichromate method (S). 